\title{
The Ongoing Debate Regarding Completion Thyroidectomy Versus Primary Thyroid Surgery for Low and Intermediate Differentiated Thyroid Carcinoma: A Meta-Analysis
}

\author{
Hyder Mirghani ${ }^{1}$, Ibrahim A. Altedlawi Albalawi II ${ }^{2}$ \\ 1. Medicine, University of Tabuk, Tabuk, SAU 2. Surgical Oncology, University of Tabuk, Tabuk, SAU
}

Corresponding author: Ibrahim A. Altedlawi Albalawi II, drbalawi@yahoo.com

\begin{abstract}
Lobectomy is increasingly performed for low-risk differentiated thyroid cancer (DTC) and papillary thyroid microcarcinoma (PTMC). However, there is a continuous controversy about completion thyroidectomy (CT) following lobectomy. The current meta-analysis aimed to assess the outcomes of the initial surgical procedure versus CT performed for low/intermediate-risk thyroid carcinoma. Six hundred and sixty-one articles were retrieved, and only 15 full texts fulfilled the inclusion and exclusion criteria. There were 15 studies, including 17,143 patients; twelve were retrospective, two prospective studies, and a controlled trial. Seven articles were from Asia, four from the USA, two from Europe, while two were published in Canada. The studies showed no difference between lobectomy and primary thyroid surgery regarding post-surgery complications. CT was not different from the initial surgical procedure in terms of complications for DTC. The study was limited by the retrospective studies included, the outcomes assessed were not uniform, and significant heterogeneity was observed. Further, well-controlled, more specific trials are needed.
\end{abstract}

Review began $11 / 13 / 2020$ Review ended 12/01/2020 Published 12/11/2020

\section{() Copyright 2020}

Mirghani et al. This is an open access article distributed under the terms of the Creative Commons Attribution License CC-BY 4.0., which permits unrestricted use, distribution, and reproduction in any medium, provided the original author and source are credited.
Categories: Oncology

Keywords: lobectomy, completion thyroidectomy, differentiated thyroid cancer

\section{Introduction}

Differentiated thyroid cancer is the fastest increasing malignancy; completion thyroidectomy (CT) for differentiated thyroid cancer is a matter of debate and controversy over many decades [1]. The rate of CT is ranging from $5-45 \%$, depending on the institution. The wide range of CT rates indicates the need for more discussion, research, and continuous updates. CT is not without complications; some centers reported complication rates in $14 \%$ of patients, including laryngeal nerve palsy (LNP), hypoparathyroidism (HPT), and hematomas [2]. The role of CT is mainly to facilitate radioactive iodine [3]. However, routine radioactive iodine is not recommended by most guidelines in low-risk DTC. Thyroid lobectomy is increasingly performed for differentiated low-risk thyroid carcinoma, but high rates of complications were reported, including hypothyroidism, which may be as high as $47 \%$ of patients, in addition to nerve palsy and bleeding. Previous literature concluded that radioactive iodine is needed in a considerable number of patients who underwent thyroid lobectomy, so a total thyroidectomy (TT) is needed, while others found no survival benefit in CT followed by radioactive iodine [1, 4]. Given the above controversy, an update is needed. Thus, the current meta-analysis aimed to compare the outcomes of the initial surgical procedures and CT in the management of DTC.

\section{Materials And Methods}

\section{Eligibility criteria according to participant, intervention, control, outcome, study design (PICOS)}

Type of Studies

Studies are eligible if they were conducted on humans, comparing the initial surgery (lobectomy or subtotal thyroidectomy) outcomes with CT, conducted for DTC, and published in English. No limitations for the study type and publication period were applied due to the limited previous meta-analyses. Animal studies were not included. DTC was defined as papillary or follicular without size specification.

\section{Inclusion Criteria}

All articles carried on adult humans, and in the English language from the first published article, up-to September 2019 were included in the study. The literature search was updated from $1^{\text {st }}$ to $31^{\text {st }}$ of October 2020. All retrospective, prospective cohorts, case-control studies, clinical trials, and randomized controlled studies on adults were included. The studied articles were not including any data on humans or animals. 
All adults who underwent surgery for DTC with a comparison between primary surgery and CT.

Type of Intervention

Studies comparing the complications of primary thyroid surgery and CT conducted for DTC.

Outcomes Measures

The articles included in the study must compare the outcomes of CT, lobectomy, or sub-total thyroidectomy conducted for DTC, including transient or permanent hypocalcemia as measures of transient and permanent hypoparathyroidism, recurrent laryngeal nerve palsy, and recurrence and metastasis.

\section{Exclusion Criteria}

Operations on children, animal studies, free survival recurrence, and mortality were not assessed. Articles published in languages other than English, if the surgery was conducted for thyroid diseases other than DTC (nodular thyroid diseases with no concomitant malignancy, medullary and anaplastic thyroid carcinomas, autoimmune thyroid diseases, or drug-induced thyroid diseases) were excluded. The details of surgical procedures (lymph node dissection, gamma signals, robotic) were not compared. The cost and hospital stay were not included in the analysis.

\section{Information sources, search and analysis methods}

An electronic literature search was carried out in PubMed ${ }^{\circledR}$ (including Epub format and publications ahead of print), Cochrane Library, EBSCO, and Google Scholar databases. The keywords used were lobectomy, completion thyroidectomy, total thyroidectomy, differentiated thyroid cancer, primary thyroid surgery, two stages of thyroid surgery, and completion thyroidectomy followed by radioactive iodine. The protean AND and OR were used. Out of the 661 articles identified, 85 records were screened, 26 full texts were assessed, and 15 studies fulfilled the inclusion and exclusion criteria.

Titles and abstracts were screened independently by the authors, full manuscripts relevant to the topic were then retrieved. Additional articles were searched and identified through hand searching of the bibliography. The retrieved full-text articles were assessed for eligibility for inclusion. A datasheet (including author's names, country, year of publication, study type, the number of patients included in each surgery arm, the study duration, and the reported outcomes after surgery) was used for data extraction. The datasheet was piloted on seven studies and then refined for the final use. Any disagreement in the selection of articles and data was discussed and solved between the researchers. Some of the studies were published more than once, the issue was discussed, and the results included when the outcomes were different. The retraction and republication was also a source of confusion that was resolved by discussion. The different phases of the search process are shown in Figure 1. 


\section{Cureus}
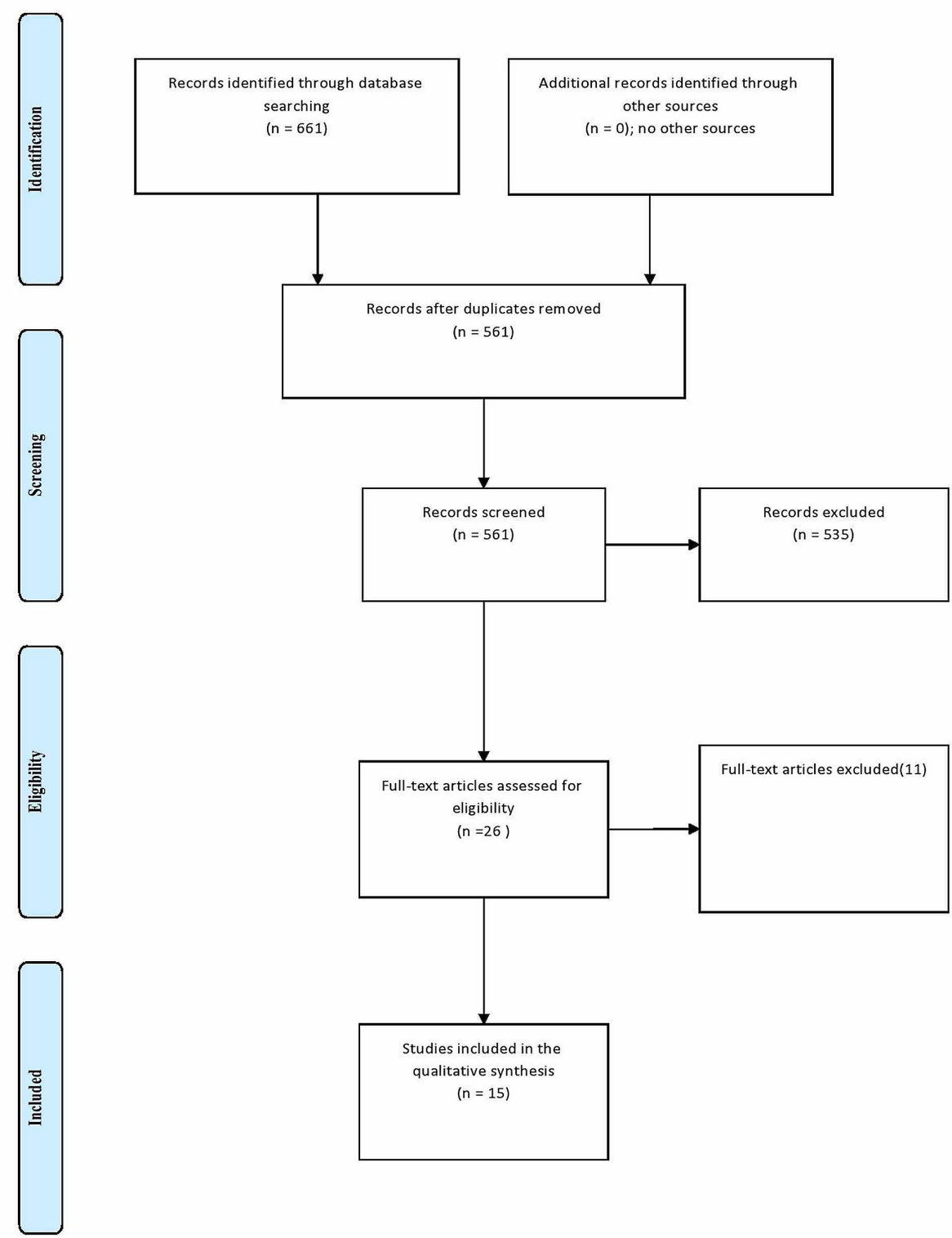

FIGURE 1: Flow diagram through the different phases of the systematic review (PRISMA flow chart)

PRISMA - Preferred Reporting Items for Systematic Reviews and Meta-Analyses

\section{Statistical Analysis}

The most recent RevMan (Cochrane Training, London, UK) for data analysis was used. The dichotomous data were entered manually, and the random effect was chosen due to the significant heterogeneity observed (more than 50\%). The sensitivity was assessed using the funnel plot. A p-value $<0.05$ was considered significant.

\section{Results}

Out of the 661 studies retrieved: 533 from PubMed, 100 from Google Scholar, 15 from Cochrane Library, and 2 from EBSCO); 650 studies were retrieved by including DTC keywords, while 11 studies were found when setting the searching engine for PTMC. The number stranded at 561 after the duplication removal; 26 full texts were screened, and only 15 studies fulfilled the inclusion and exclusion criteria (one study was excluded due to the zero results of complications in both arms [5], the results of another study were converted from percentages to numbers due to unavailability of the full text [6]). The studies period ranged from 3-24 years. Twelve were retrospective, two prospective studies, and one controlled trial. Seven articles were from Asia, four from the USA, two from Europe, while two were published in Canada. The present metaanalysis included 17,143 patients (11,797 in the control arm and 5,346 in the interventional group). In the 


\section{Cureus}

current meta-analysis, five studies favored lobectomy [6-10], another five stand neutral [11-15], and four were against lobectomy [16-19]. Included studies and outcomes are presented in Tables 1-2. Significant heterogeneity was observed (90\%), as showed in Figure 2. The funnel test showed significant asymmetry (Figure 3). Thus, the random effect was applied (odds ratio [OR], 0.98; 95\% CI, 0.49-1.95). The overall effect was neutral, $\mathrm{p}=0.95)$.

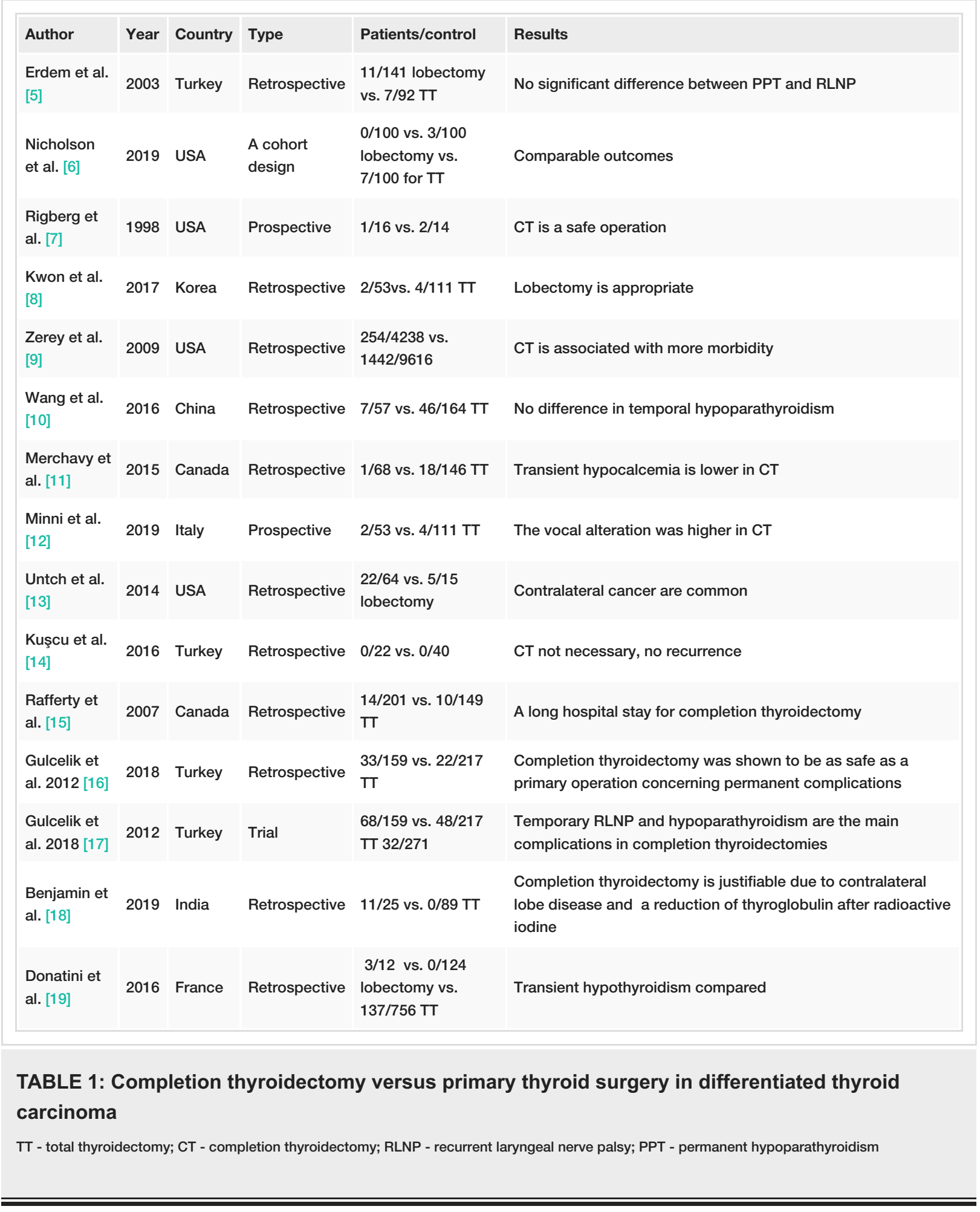




\section{Cureus}

\begin{tabular}{|c|c|c|c|}
\hline Author & Study period & $\begin{array}{l}\text { Reason for initial } \\
\text { surgery }\end{array}$ & Outcomes measured \\
\hline Untch et al. [5] & $\begin{array}{l}10 \text { years } \\
\text { records }\end{array}$ & LGDTC & Oncologic outcomes \\
\hline Merchavy et al. [6] & $\begin{array}{l}5 \text { years of } \\
\text { records }\end{array}$ & DTC & Transient hypocalcemia and permanent hypoparathyroidism \\
\hline Rigberg et al. [7] & Not stated & DTC & Transient hypocalcemia, and transient recurrent laryngeal palsy \\
\hline Erdem et al. [8] & 8 years & DTC & Permanent hypoparathyroidism and recurrent laryngeal palsy \\
\hline Rafferty et al. [9] & $\begin{array}{l}10 \text { years } \\
\text { records }\end{array}$ & Multinodular goiter & Permanent hypoparathyroidism and recurrent laryngeal palsy \\
\hline Zerev et al. [10] & 5 years & DTC & Cost and hospital stay \\
\hline $\begin{array}{l}\text { Gulcelik et al. } \\
2012 \text { [11] }\end{array}$ & $\begin{array}{l}5 \text { years of } \\
\text { records }\end{array}$ & DTC & $\begin{array}{l}\text { Transient hypocalcemia, permanent hypoparathyroidism, and } \\
\text { recurrent laryngeal palsy }\end{array}$ \\
\hline Donatini et al. [12] & $\begin{array}{l}24 \text { years } \\
\text { records }\end{array}$ & PTMC & Transient hypocalcemia and transient recurrent laryngeal palsy \\
\hline Wang et al. [13] & $\begin{array}{l}3 \text { years of } \\
\text { records }\end{array}$ & DTC & Transient hypocalcemia \\
\hline $\begin{array}{l}\text { Gulcelik et al. } \\
2012[14]\end{array}$ & 10 years & DTC & $\begin{array}{l}\text { Transient hypocalcemia, permanent hypoparathyroidism, and } \\
\text { recurrent laryngeal palsy }\end{array}$ \\
\hline Kuşcu et al. [15] & $\begin{array}{l}15 \text { years } \\
\text { records }\end{array}$ & PTMC & Recurrence \\
\hline Kwon et al. [16] & 8.5 years & PTMC & $\begin{array}{l}\text { Transient hypocalcemia, permanent hypoparathyroidism, and } \\
\text { recurrence-free survival }\end{array}$ \\
\hline $\begin{array}{l}\text { Nicholson et al. } \\
{[17]}\end{array}$ & 10 years & DTC & $\begin{array}{l}\text { Transient hypocalcemia, permanent hypoparathyroidism, and } \\
\text { recurrent laryngeal palsy }\end{array}$ \\
\hline $\begin{array}{l}\text { Benjamin et al. } \\
{[18]}\end{array}$ & $\begin{array}{l}6 \text { years of } \\
\text { records }\end{array}$ & LGDTC & Recurrence rate \\
\hline Minni et al. [19] & $\begin{array}{l}2 \text { years } \\
\text { prospective }\end{array}$ & $\begin{array}{l}\text { Multinodular or } \\
\text { LGDTC }\end{array}$ & External branch of superior laryngeal nerve injury \\
\hline
\end{tabular}

\section{TABLE 2: The reason and outcomes of the completion thyroidectomy}

TH - transient hypocalcemia; PHPT - permanent hypoparathyroidism; TRLNV - transient recurrent laryngeal palsy; PRLNV - permanent recurrent laryngeal palsy; LGDTC - low-grade differentiated thyroid carcinoma; DTC - differentiated thyroid carcinoma; LGDTC - low-grade differentiated thyroid carcinoma; PTMC - papillary thyroid microcarcinoma

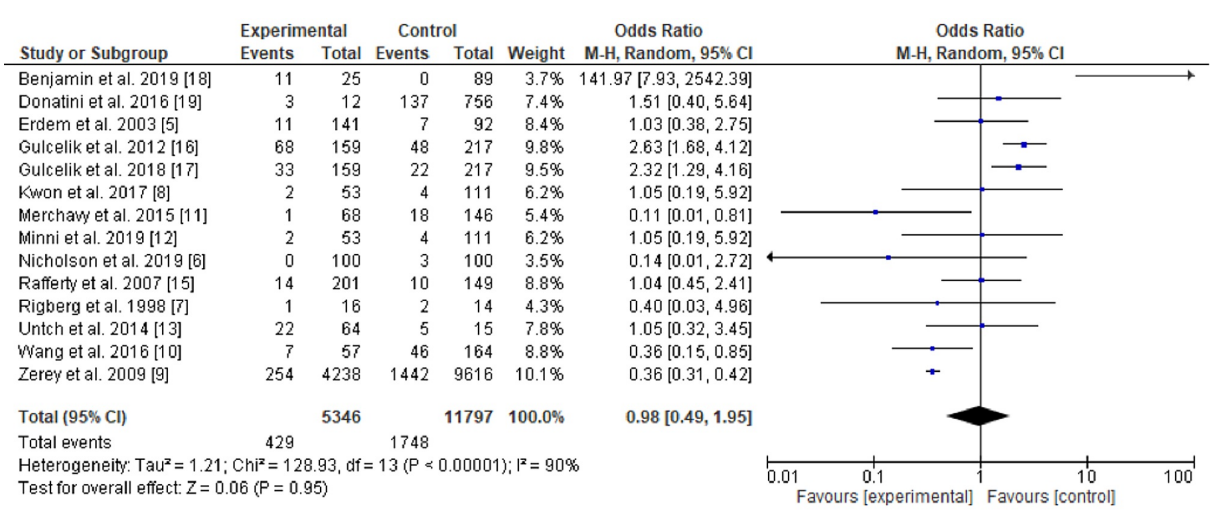

FIGURE 2: A comparison between primary thyroid surgery and completion thyroidectomy for low/intermediate-risk differentiated 


\section{thyroid carcinoma}

M-H - Mantel-Haenszel, Tau ${ }^{2}$ - cross-study variation due to heterogeneity; $\mathrm{Chi}^{2}$ - Chi-square; $\mathrm{I}^{2}$ - percentage of variations across studies; $Z$ - test of the null hypothesis; df - degrees of freedom

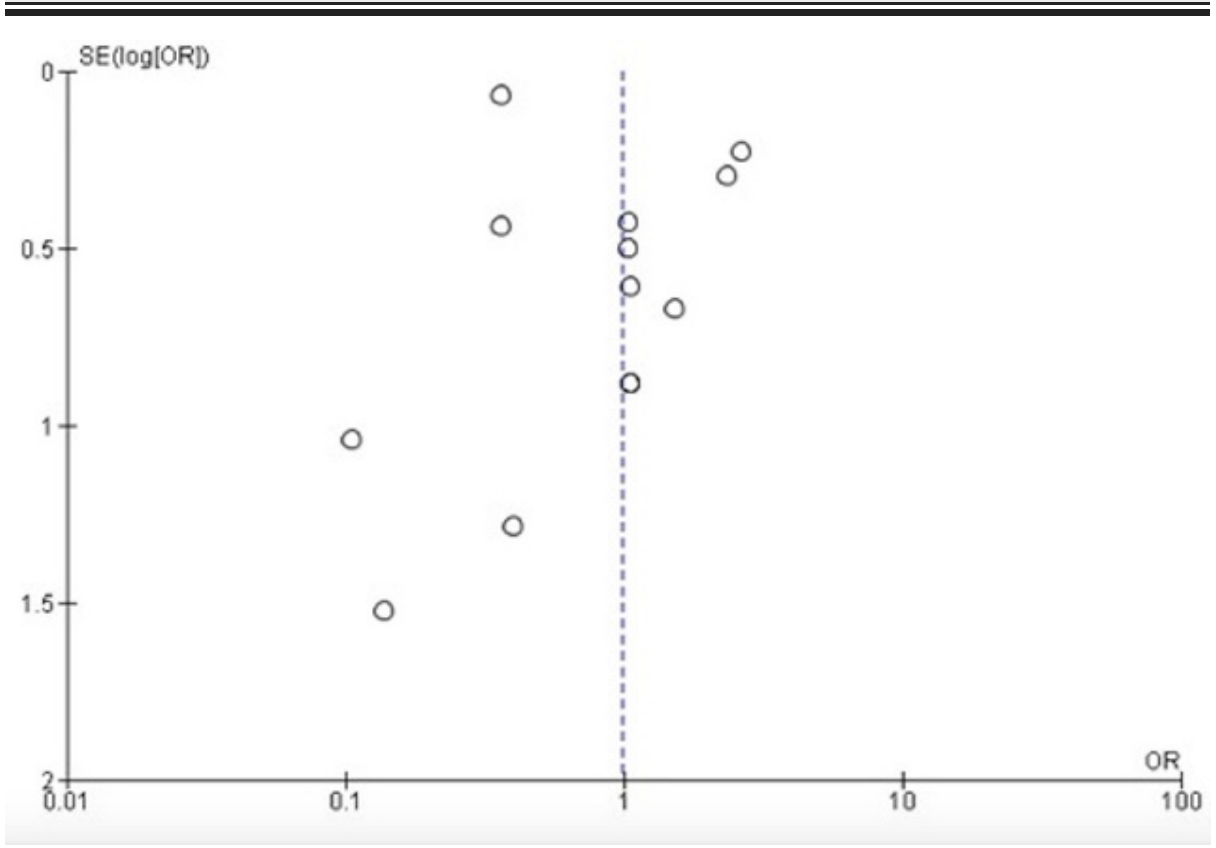

FIGURE 3: Funnel plot of total thyroidectomy versus completion thyroidectomy for low/intermediate-risk differentiated thyroid carcinoma and papillary thyroid microcarcinoma

SE (log[OR]) - standard error of the log odds ratio; OR - odds ratio

\section{Discussion}

Differentiated thyroid carcinoma is rising worldwide, mainly due to the increase in screening and overdiagnosis. The increasing rate of DTC is mirrored by increasing both primary and completion thyroidectomy [20,21]. The present data showed that the initial operation (total thyroidectomy [TT] or lobectomy) carries the same outcomes in transient hypocalcemia (TH), permanent hypoparathyroidism (PHPT), recurrent laryngeal nerve (RCLN), and RCLN injury. However, the evidence is weak because most of the included studies were retrospective. Besides, the significant heterogeneity observed might affect the result. Our findings supported a previous meta-analysis published by Li and colleagues, which assessed transient and permanent hypocalcemia, RLN injury, hematoma, and wound infection. Li et al. study is limited by the small number of the studies included, the limited databases searched, and the period of their search [18]. Our result implies that the surgeon might choose either lobectomy with careful follow-up for recurrence or total thyroidectomy. A careful patient's assessment for risk stratification, a well-informed, preference-based decision, and the surgeon experience might direct the extent of the initial thyroid surgery for DTC [22, 23].

Reviews and meta-analyses evaluating completion thyroidectomy versus the initial surgery are scarce. Thyroid surgeries are increasingly performed due to improving diagnostic techniques, screening, or true increasing rates [24, 25]. In addition, the high body mass index has dramatically increased and was found to be associated with DTC in a large case-control study (frequency-matched) that included 10,668 DTC patients versus 11,858 control [26]. Given the above, an update is highly needed.

There are several limitations of the current study. We included both prospective and retrospective studies; the included studies cannot control for various confounders that may affect the outcomes, including the original thyroid disease, the patient's age, comorbidities, and the extent of surgery, including central lymph nodes dissection [27]. Besides, a high-volume surgical team might affect the outcomes [28]. Also, the limitations include the significant observed heterogeneity and studies published only in the English language.

\section{Conclusions}


Completion thyroidectomy was comparable to initial thyroid surgery (in terms of transient or permanent hyperparathyroidism and recurrent laryngeal nerve injury) when applied for differentiated thyroid cancer and papillary thyroid microcarcinoma. The surgeon might choose between total thyroidectomy and lobectomy as initial surgery for the same disease. The current data gave an insight into the current knowledge regarding thyroid surgery for low-grade differentiated thyroid carcinoma and papillary thyroid microcarcinoma. It was limited by the retrospective studies included, the outcomes assessed were not uniform, and significant heterogeneity was observed. Further, well-controlled, more specific trials are needed.

\section{Additional Information \\ Disclosures}

Human subjects: All authors have confirmed that this study did not involve human participants or tissue. Animal subjects: All authors have confirmed that this study did not involve animal subjects or tissue. Conflicts of interest: In compliance with the ICMJE uniform disclosure form, all authors declare the following: Payment/services info: All authors have declared that no financial support was received from any organization for the submitted work. Financial relationships: All authors have declared that they have no financial relationships at present or within the previous three years with any organizations that might have an interest in the submitted work. Other relationships: All authors have declared that there are no other relationships or activities that could appear to have influenced the submitted work.

\section{References}

1. Zambeli-Ljepović A, Wang F, Dinan MA, et al.: Low-risk thyroid cancer in elderly: total thyroidectomy/RAI predominates but lacks survival advantage. J Surg Res. 2019, 248:189-197. 10.1016/j.jss.2019.05.029

2. Shaha AR, Tuttle MR: Completion thyroidectomy-indications and complications. Eur J Surg Oncol. 2019, 45:1129-1131. 10.1016/j.ejso.2019.03.028

3. Balentine CJ, Domingo RP, Patel R, Laucirica R, Suliburk JW: Thyroid lobectomy for indeterminate FNA: not without consequences. J Surg Res. 2013, 184:189-192. 10.1016/j.jss.2013.05.076

4. Kluijfhout WP, Pasternak JD, Drake FT, et al.: Application of the new American Thyroid Association guidelines leads to a substantial rate of completion total thyroidectomy to enable adjuvant radioactive iodine. Surgery. 2017, 161:127-133. 10.1016/j.surg.2016.05.056

5. Erdem E, Gülçelik MA, Kuru B, Alagöl H: Comparison of completion thyroidectomy and primary surgery for differentiated thyroid carcinoma. Eur J Surg Oncol. 2003, 29:747-749. 10.1016/j.ejso.2003.08.006

6. Nicholson KJ, Teng CY, McCoy KL, et al.: Completion thyroidectomy: a risky undertaking? . Am J Surg. 2019, 218:695-699. 10.1016/j.amjsurg.2019.07.014

7. Rigberg D, Chandler C, Ashley S, Zuckerbraun L, Thompson J: Safety of completion thyroidectomy for multicentric carcinoma. Am Surg. 1998, 64:189-191.

8. Kwon H, Jeon MJ, Kim WG, et al.: A comparison of lobectomy and total thyroidectomy in patients with papillary thyroid microcarcinoma: a retrospective individual risk factor-matched cohort study. Eur J Endocrinol. 2017, 176:371-378. 10.1530/EJE-16-0845

9. Zerey M, Prabhu AS, Newcomb WL, Lincourt AE, Kercher KW, Heniford BT: Short-term outcomes after unilateral versus complete thyroidectomy for malignancy: a national perspective. Am Surg. 2009, 75:20-24.

10. Wang X, Xing T, Wei T, et al.: Completion thyroidectomy and total thyroidectomy for differentiated thyroid cancer: comparison and prediction of postoperative hypoparathyroidism. J Surg Oncol. 2016, 113:522-525.

11. Merchavy S, Marom T, Forest VI, et al.: Comparison of the incidence of postoperative hypocalcemia following total thyroidectomy vs completion thyroidectomy. Otolaryngol Head Neck Surg. 2015, 152:53-56. $10.1177 / 0194599814556250$

12. Minni A, Rosati D, Cavaliere C, et al.: Total versus completion thyroidectomy: a multidimensional evaluation of long-term vocal alterations. Ear Nose Throat J. 2019, 10.1177/0145561319886156

13. Untch BR, Palmer FL, Ganly I, et al.: Oncologic outcomes after completion thyroidectomy for patients with well-differentiated thyroid carcinoma. Ann Surg Oncol. 2014, 21:1374-1378. 10.1245/s10434-013-3428-1

14. Kuşcu O, Önay Ö, Kayahan B, Süslü N, Yılmaz T: The rising incidence of papillary thyroid microcarcinoma and is completion surgery necessary or not?. Otolaryngol Pol. 2016, 30:14-18. 10.5604/00306657.1199990

15. Rafferty MA, Goldstein DP, Rotstein L, et al.: Completion thyroidectomy versus total thyroidectomy: is there a difference in complication rates? An analysis of 350 patients. J Am Coll Surg. 2007, 205:602-607. 10.1016/j.jamcollsurg.2007.05.030

16. Gulcelik MA, Kuru B, Dincer H, et al.: Complications of completion versus total thyroidectomy . Asian Pac J Cancer Prev. 2012, 13:5225-5228. 10.7314/APJCP.2012.13.10.5225

17. Gulcelik MA, Dogan L, Akgul GG, Güven EH, Ersöz Gulcelik N: Completion thyroidectomy: safer than thought. Oncol Res Treat. 2018, 41:386-390. 10.1159/000487083

18. Benjamin J, Hephzibah J, Cherian AJ, Mathew D, Shanthly N, Oommen R: Is hemi-thyroidectomy adequate in low risk differentiated thyroid cancer?. World J Nucl Med. 2019, 18:171-175. 10.4103/wjnm.WJNM_70_18

19. Donatini G, Castagnet M, Desurmont T, Rudolph N, Othman D, Kraimps JL: Partial thyroidectomy for papillary thyroid microcarcinoma: is completion total thyroidectomyindicated?. World J Surg. 2016, 40:510515. 10.1007/s00268-015-3327-7

20. Albalawi IA, Mirghani HO: Pattern and temporal profile of thyroid carcinoma in the Kingdom of Saudi Arabia: A review and meta-analysis. AMJ. 2019, 12:356-363. 10.35841/1836-1935.12.12.356-363

21. Li YJ, Wang YZ, Yi ZB, Chen LL, Zhou XD: Comparison of completion thyroidectomy and primary total surgery for differentiated thyroid cancer: a meta-analysis. Oncol Res Treat. 2015, 38:528-531. $10.1159 / 000440690$

22. Price AK, Randle RW, Schneider DF, Sippel RS, Pitt SC: Papillary thyroid microcarcinoma: decision-making, 


\section{Cureus}

extent of surgery, and outcomes. J Surg Res. 2017, 218:237-245. 10.1016/j.jss.2017.05.054

23. Park JH, Yoon JH: Lobectomy in patients with differentiated thyroid cancer: indications and follow-up . Endocr Relat Cancer. 2019, 26:381-393. 10.1530/ERC-19-0085

24. Lim H, Devesa SS, Sosa JA, Check D, Kitahara CM: Trends in thyroid cancer incidence and mortality in the United States, 1974-2013. JAMA. 2017, 317:1338-1348. 10.1001/jama.2017.2719

25. Haymart MR, Reyes-Gastelum D, Caoili E, Norton EC, Banerjee M: The relationship between imaging and thyroid cancer diagnosis and survival. Oncologist. 2020, 23:765-771. 10.1634/theoncologist.2020-0159

26. He Q, Sun H, Li F, Liang N: Obesity and risk of differentiated thyroid cancer: a large-scale case-control study. Clin Endocrinol. 2019, 91:869-878. 10.1111/cen.14091

27. Meltzer C, Klau M, Gurushanthaiah D, et al.: Risk of complications after thyroidectomy and parathyroidectomy: a case series with planned chart review. Otolaryngol Head Neck Surg. 2016, 155:391401. 10.1177/0194599816644727

28. Lorenz K, Raffaeli M, Barczyński M, Lorente-Poch L, Sancho J: Volume, outcomes, and quality standards in thyroid surgery: an evidence-based analysis-European Society of Endocrine Surgeons (ESES) positional statement. Langenbecks Arch Surg. 2020, 405:401-425. 10.1007/s00423-020-01907-x 